\title{
Quantitative estimation of cilnidipine and valsartan in rat plasma by RP-HPLC: its pharmacokinetic application
}

\author{
Ramanlal N. Kachave ${ }^{1 *}$ D, Shanker S. Yelmame ${ }^{2}$ and Akshay G. Mundhe ${ }^{2}$
}

\begin{abstract}
Background: Cilnidipine (CLD) and valsartan (VAL) are antihypertensive agents used in the treatment of hypertension. So, pharmacokinetic study of CLD and VAL in rat plasma was carried out using chromatographic method. The chromatographic separation was performed on the Inertsil ODS column, using mobile phase methanol: water 85:15 v/v (pH 3.0) at the flow rate of $1.1 \mathrm{~mL} / \mathrm{min}$., detected at $254 \mathrm{~nm}$.
\end{abstract}

Result: Cilnidipine (CLD) (1 mg/kg) and valsartan (VAL) $(1 \mathrm{mg} / \mathrm{kg})$ was administered orally in rats, and blood samples were collected at time intervals of $0,0.5,1,2,3,4,5,6,7,8,10,12$, and $24 \mathrm{~h}$ after dosing. The retention time of plasma, CLD, and VAL was found to be $2.7,6.6$, and $4.3 \mathrm{~min}$, respectively. The result was validated statistically and by recovery studies. Linearity was acceptable in the range of $1-5$ and $8-40 \mu \mathrm{g} / \mathrm{mL}$ for CLD and VAL, respectively. Maximal concentration $\left(C_{\max }\right)$ of CLD and VAL was observed to be $338 \pm 13.85$ and $1282.21 \pm 39.23(\mathrm{ng} / \mathrm{mL})$. The half-life of CLD and VAL was found to be $1.08 \pm 0.21$ and $1.43 \pm 0.12 \mathrm{~h}$, respectively.

Conclusion: The present method was successfully applied to the pharmacokinetic study of cilnidipine (CLD) and valsartan (VAL) in rat plasma after oral administration.

Keywords: Cilnidipine, Valsartan, RP-HPLC, Rat plasma, $T_{\max } C_{\max }$

\section{Background}

Hypertension is one of the risk factors for cardiovascular diseases, including ischemic and hemorrhagic stroke, dementia, heart failure, vision loss, and kidney failure. Sign of multiple underlying physiological abnormalities in elevated vital signs. Cilnidipine (CLD, Fig. 1a) is a unique calcium channel blocker used for hypertension which inhibits sympathetic voltage channels additionally to vascular dihydropyridine channel. Intracellular calcium influx is prevented by cilnidipine leading to vasodilatation. Cilnidipine possesses superior selectivity for vascular smooth muscle cells [1, 2]. Valsartan (VAL, Fig. 1b) belongs to a category of medicine called

\footnotetext{
* Correspondence: ramanlalkachave26@gmail.com

'Department of Pharmaceutical Chemistry, Amrutvahini College of Pharmacy, Affiliated Savitribai Phule Pune University, Sangamner, Maharashtra 422608, India

Full list of author information is available at the end of the article
}

angiotensin receptor blockers (ARBs). It works by relaxing blood vessels so that blood can flow more easily. Valsartan blocks the vasoconstrictor and aldosteronesecreting effects of angiotensin II by selectively blocking the binding of angiotensin II to the AT1 receptor in many tissues, like vascular smooth muscle and therefore the adrenal gland [3, 4] just in case with treatment of hypertension target blood pressures can't be achieved enough by use of one antihypertensive agent, and thus combination therapy is used having a different mechanism of action. Additionally, there are many patients with hypertension who take other medicines concomitantly with antihypertensive agents $[3,5-7]$. The literature survey of CLD and VAL revealed various methods are used for analysis of CLD alone and together with other antihypertensive agents such as LC-MS [8, 9], UPLC [10], and RP-HPLC [11], while for VAL alone or together with other antihypertensive agents, methods like UPLC 
<smiles>COCCOC(=O)C1=C(C)NC(C)=C(C(=O)OC/C=C/c2ccccc2)C1c1cccc([N+](=O)[O-])c1</smiles>

a: Clinidipne<smiles>CCCCC(=O)N(Cc1ccc(-c2ccccc2-c2nn[nH]n2)cc1)C(C(=O)O)C(C)C</smiles>

b: Valsartan

Fig. $1 \mathbf{a}$, b The chemical structure of CLD and VAL

[12-14], stability indicating assay method by HPLCDAD [15], LC-MS/MS [16-19], and LC-florescence detector [20] were reported. The tactic was developed to offer an easy, reliable, and validated bioanalytical method for the pharmacokinetic study of CLD and VAL in synthetic mixture. In the present research work, a successful attempt was made for determination of cilnidipine and valsartan in pharmaceutical tablet dosage form by reversed-phase high-performance liquid chromatography (RP-HPLC) in rat plasma. The method was developed by experimentation, based on literature survey and ascertained by statistical parameter of sampling. The simplicity, rapidity, and reproducibility of the proposed method completely fulfilled the objective of this research work. The developed method was applied successfully for pharmacokinetic studies of cilnidipine and valsartan in rats. The applicability of method suggests its further application for bioequivalence, bioavailability, and drug interaction studies. A simple and inexpensive liquid-liquid extraction procedure and an isocratic chromatography condition using a reversed phase column provided an assay well suited for real-time analyses. The developed RP-HPLC method has many advantages such as simple, accurate, sensitive, and precise for quality control and routine analysis of CLD and VAL combination. The method was compared with the previous pharmacokinetic method developed by Lee et al. [7] and located to be reliable.

\section{Method}

\section{Chemicals and reagents}

Cilnidipine and valsartan gift samples were obtained from J. B. Chemicals and Pharmaceuticals, Hyderabad, India, and Lupin Pharmaceutical Ltd., India, respectively. The purity of CLD is $99 \%$ and VAL is $98-102 \%$. HPLCgrade acetonitrile and methanol were procured from Merck (Mumbai, India). Analytical reagent-grade (AR) triethylamine and orthophosphoric acid were also procured from SD fine chemicals (Mumbai, India).

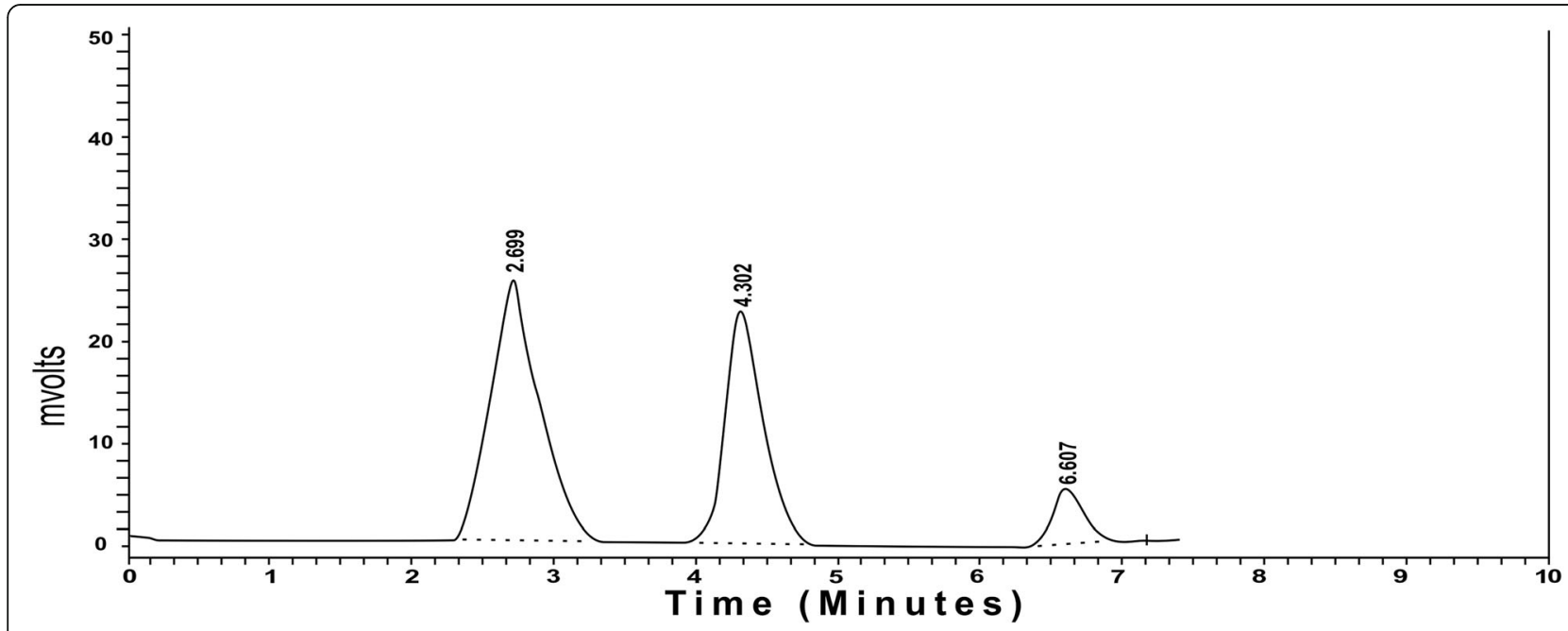

Fig. 2 Optimized chromatogram of cilnidipine and valsartan in spiked rat plasma in methanol to water (85:15, v/v, pH 3.0 adjusted with orthophosphoric acid) 
Table 1 The calibration curves for cilnidipine and valsartan

\begin{tabular}{lll}
\hline Parameters & CLD & VAL \\
\hline Slope & 110.1 & 36.92 \\
Y-intercept & 0.74 & -8.916 \\
Correlation coefficient & 0.999 & 0.999 \\
Regression equation & $y=110.1 \times+0.74$ & $y=36.92 \times-8.916$ \\
Linearity range & $1-5 \mu \mathrm{g} / \mathrm{mL}$ & $8-40 \mu \mathrm{g} / \mathrm{mL}$ \\
LOD & $0.023 \mu \mathrm{g} / \mathrm{mL}$ & $0.069 \mu \mathrm{g} / \mathrm{mL}$ \\
LOQ & $0.078 \mu \mathrm{g} / \mathrm{mL}$ & $0.235 \mu \mathrm{g} / \mathrm{mL}$ \\
\hline
\end{tabular}

\section{Instrumentation}

HPLC (Waters 600 controllers) instrument equipped with a model code 6CE In-Line Degasser Af, reciprocating pump, Rheodyne 7725i Manual Injector with a $20-\mu$ lixed loop and HPLC syringe of $100 \mu \mathrm{l}$, using a UV-visible detector, was used for separation and quantitation.

\section{Chromatographic condition}

Chromatographic separation was achieved on RP-18, Inertsil ODS column, $(250 \mathrm{~mm} \times 4.6 \mathrm{~mm} \times 5 \mu)$, particle size $5 \mu \mathrm{m}$. The mobile phase used for separation of analytes was methanol to water, adjusted at $\mathrm{pH} 3.0$ with orthophosphoric acid in the ratio 85:15 (v/v) used throughout the analysis. The flow rate of the mobile phase was $1.1 \mathrm{~mL} / \mathrm{min}$, using injection volume $20 \mu \mathrm{l}$ of analyte and detected at $254 \mathrm{~nm}$, as shown in Fig. 2.

\section{Preparation standard solutions}

The standard calibration curve was carried out by preparing primary stock solutions using QC samples which were weighed separately and prepared for a concentration of cilnidipine $(1 \mathrm{mg} / \mathrm{mL})$ and valsartan $(1 \mathrm{mg} / \mathrm{mL})$ using methanol as solvent. Working standard solutions were prepared by transferring different volumes of $0.1-$ $0.5 \mathrm{~mL}$ stock of CLD and $0.8-4 \mathrm{~mL}$ stock of VAL using a mixture of methanol and water $\mathrm{pH} 3.0(85: 15 \mathrm{v} / \mathrm{v})$ as a diluent.

\section{Preparation of CC standards and QC samples}

Working standard solutions of 1-5 ppm of CLD and 8$40 \mathrm{ppm}$ of VAL were prepared from the stock solution. Volumes of $20 \mu \mathrm{l}$ of working standard solution were

Table 2 Mean value of system suitability study

\begin{tabular}{lll}
\hline Parameters & CLD & VAL \\
\hline HETP & 0.1024 & 0.2372 \\
Retention time & $6.6 \pm 0.01$ & $4.3 \pm 0.02$ \\
Tailing factor & $1.37 \pm 0.02$ & $1.45 \pm 0.02$ \\
Resolution & $13.66 \pm 0.15$ & $9.36 \pm 0.14$ \\
\hline
\end{tabular}

Table 3 Recovery study

\begin{tabular}{lllll}
\hline Drug & $\begin{array}{l}\text { Amount } \\
\text { took } \\
(\boldsymbol{\mu} \mathbf{g} / \mathrm{mL})\end{array}$ & $\begin{array}{l}\text { Amount } \\
\text { added } \\
(\boldsymbol{\mu} \mathbf{g} / \mathbf{m L})\end{array}$ & $\begin{array}{l}\text { Amount } \\
\text { found } \\
(\boldsymbol{\mu g} / \mathbf{m L})\end{array}$ & \% Recovery \\
\hline CLD & 2.0 & 1.6 & $1.582 \pm 0.03$ & $98.87 \pm 2.08$ \\
& & 2.0 & $2.008 \pm 0.05$ & $100.4 \pm 1.58$ \\
& & 2.4 & $2.396 \pm 0.03$ & $99.83 \pm 1.54$ \\
VAL & 16 & 12.8 & $12.62 \pm 0.26$ & $98.59 \pm 2.07$ \\
& & 16 & $16.02 \pm 0.04$ & $100.12 \pm 0.29$ \\
& & 19.2 & $19.16 \pm 0.07$ & $99.79 \pm 0.40$ \\
\hline
\end{tabular}

added to $500 \mu \mathrm{l}$ of plasma to obtain drug concentration levels of $1-5 \mu \mathrm{g} / \mathrm{mL}$ and $8-40 \mu \mathrm{g} / \mathrm{mL}$ for cilnidipine and valsartan, respectively. Quality control samples were prepared separately and pooled at three different concentration levels of 1,3 , and $5 \mu \mathrm{g} / \mathrm{mL}$ and 8,24 , and $40 \mu \mathrm{g} / \mathrm{mL}$ for cilnidipine and valsartan as low, medium, and high, respectively.

\section{Preparation of plasma sample}

Before processing the stored plasma samples, they were allowed to soften at room temperature. A liquid-liquid extraction procedure was used for the extraction of drugs from plasma. $\mathrm{ACN}$ is used as an extracting solvent. Plasma was centrifuged at $4000-4500 \mathrm{rpm}$. For $10 \mathrm{~min}$, an aliquot $(0.5 \mathrm{~mL})$ was pipetted into a $10-\mathrm{mL}$ polypropylene tube and acetonitrile $(2.0 \mathrm{~mL})$ was added. The mixture was vortex mixed briefly and after standing for $5 \mathrm{~min}$ at room temperature the mixture was centrifuged at 7000-7500 rpm for $10 \mathrm{~min}$. The supernatant was carefully transferred into vials filtered through a syringe filter $0.2 \mu \mathrm{m}$ and then injected into the HPLC system.

\section{Method validation}

The proposed analytical method was validated according to US FDA guidelines [21]. The assay was validated for specificity, linearity, accuracy, and precision. Six different lots of rat plasma samples were taken and the specificity of the method was determined. The interfering substances or background noises responses at the retention time of cilnidipine and valsartan were acceptable less than $20 \%$ of the response of the lower limit of quantification (LLOQ). Linearity was performed in the concentration range for cilnidipine and valsartan from 1000 to $5000 \mathrm{ng} / \mathrm{mL}$ and 8000 to 40,000 ng/mL, respectively. For

Table 4 Intraday precision for cilnidipine

\begin{tabular}{lll}
\hline Statistical data & CLD & VAL \\
\hline Mean & 100.03 & 99.60 \\
S.D. & 0.56 & 0.076 \\
\%R.S.D. & 0.569 & 0.0764 \\
\hline
\end{tabular}


Table $\mathbf{5}$ Intermediate precision

\begin{tabular}{lllll}
\hline $\begin{array}{llll}\text { Statistical } \\
\text { data }\end{array}$ & CLD & & VAL & \\
\cline { 2 - 5 } & Day to day & Analyst to analyst & & Analyst to analyst \\
\hline Mean & 99.82 & 99.25 & 99.75 & 99.56 \\
S.D. & 0.06 & 0.268 & 0.12 & 0.20 \\
\%R.S.D. & 0.0656 & 0.271 & 0.126 & 0.208 \\
\hline
\end{tabular}

the determination of linearity, standard calibration curves containing five points were plotted and checked. The volume of biological matrix precision was carried out using five independent sample preparations of a single lot of bulk drug and formulation. Minimum three concentrations in the range of excepted study were recommended. The precision is determined at each concentration level which does not exceed $15 \%$ of the coefficient of variance (CV) except for the LLOQ, where it should not exceed $20 \%$ of the CV.

\section{Result}

\section{Selectivity}

Selectivity is the ability of an analytical method to differentiate and quantify the analyte in the presence of other component in the sample. Analysis of blank samples of the appropriate biological matrix of six samples. Each blank sample should be tested for interference and selectivity should be ensured at the LLOQ. If the method is intended to quantify, more than one analyte should be tested to ensure that there is no interference. Six individual rat blank plasma samples were analyzed for investigation of selectivity of the method. Each blank sample was tested for interference using the present analytical method and it was compared with spiked samples whose concentration of the analyte was at the LLOQ.

\section{Linearity}

The linearity was performed by making appropriate working stock solutions with the mobile phase to obtain concentration ranging from 1 to $5 \mu \mathrm{g} / \mathrm{mL}$ of cilnidipine and 8 to $40 \mu \mathrm{g} / \mathrm{mL}$ of valsartan. The calibration curves were plotted with observed peak areas against concentration followed by the determination of regression equations and calculation of the correlation coefficients. Limit of detection and quantification of CLD and VAL were found to be $0.023 \mu \mathrm{g} / \mathrm{mL}$ and $0.069 \mu \mathrm{g} / \mathrm{mL}$, and $0.078 \mu \mathrm{g} / \mathrm{mL}$ and $0.235 \mu \mathrm{g} / \mathrm{mL}$, respectively. The result is shown in Table 1.

\section{System suitability study}

System suitability parameters such as retention time, HETP, resolution, and peak tailing are determined. The results obtained are shown in Table 2.

\section{Recovery study}

The recovery study was performed by comparing the analytical result for extracted samples at three different concentrations (low, medium, and high) with an unextracted standard that represents $100 \%$ recovery, as shown in Table 3.

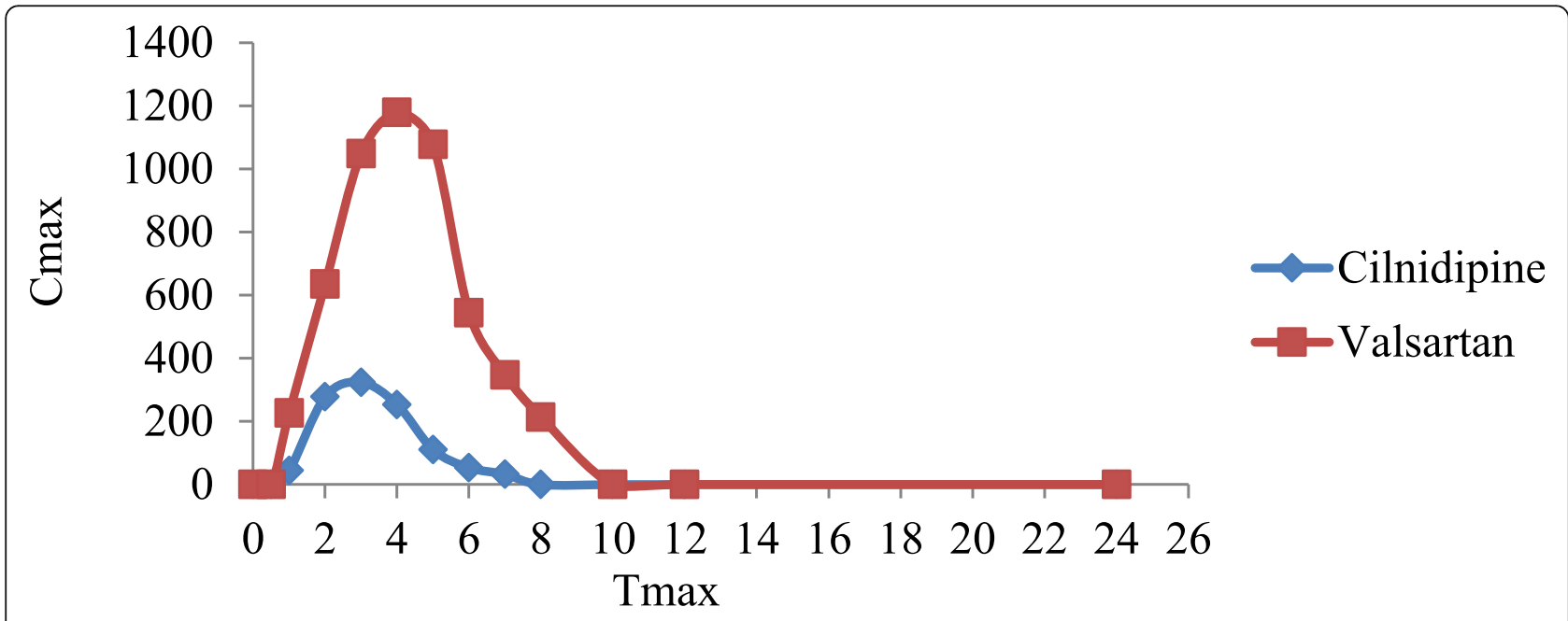

Fig. 3 Mean plasma concentration-time profile CLD and VAL 
Table 6 Pharmacokinetic parameters

\begin{tabular}{lll}
\hline Parameters & CLD & VAL \\
\hline$C_{\text {max }}(\mathrm{ng} / \mathrm{mL})$ & $338 \pm 13.85$ & $1282.21 \pm 39.23$ \\
$T_{\max }(\mathrm{h})$ & $3.0 \pm 0.81$ & $4.0 \pm 0.89$ \\
AUC $_{\text {last }}(\mathrm{ng} / \mathrm{mL})$ & $1069.04 \pm 36.93$ & $5132.8 \pm 76.76$ \\
$\mathrm{AUC}_{\text {extra }}(\mathrm{ng} / \mathrm{mL} \mathrm{h})$ & $51.94 \pm 22.28$ & $452.19 \pm 84.32$ \\
AUC $_{0-\infty}(\mathrm{ng} / \mathrm{mL})$ & $1117.84 \pm 54.90$ & $5584.89 \pm 125.7$ \\
Half-life $(\mathrm{h})$ & $1.08 \pm 0.21$ & $1.43 \pm 0.12$ \\
\hline
\end{tabular}

\section{Precision}

\section{Repeatability}

The repeatability was performed for three replicate at five concentrations in linearity range $1-5 \mu \mathrm{g} / \mathrm{mL}$ for cilnidipine and $8-40 \mu \mathrm{g} / \mathrm{mL}$ for valsartan. Results of repeatability for cilnidipine and valsartan are reported in Table 4.

\section{Intermediate precision}

It was performed within laboratory variation on a different day in three replicates at three different concentrations. A result of day to day variation and analyst to analyst variation was performed. Cilnidipine and valsartan are reported in Table 5.

\section{Robustness}

The capacity of a method to remain unafected by small delibrate varitations in method parameters, the RSD of peak areas of Cilnidipine and Valsartan were found to be well within the acceptable limit of $2 \%$. The tailing factor for both the peaks was found to be (Symmetrical) $<1.5$.

\section{$\angle O D$ and $\angle O Q$}

The developed method has calculated the limit of detection and quantification based on the standard deviation response and slope of the linearity curve.

\section{Plasma estimation of cilnidipine and valsartan in rat plasma}

The plasma concentrations of cilnidipine and valsartan vs time are shown in Fig. 3 . The $C_{\max }$ and $T_{\max }$ after oral administration of cilnidipine and valsartan were $338 \pm$ 13.85 and $1282.21 \pm 39 \mathrm{ng} / \mathrm{ml}, 3$ and $6 \mathrm{~h}$, respectively. The biological half-life $\left(t_{1 / 2}\right)$ of cilnidipine and valsartan was $1.08 \pm 0.21$ and $1.43 \pm 0.12 \mathrm{~h}$, respectively. The result is shown in Table 6.

\section{Discussion \\ Pharmacokinetic applications}

The developed method has been successfully applied to quantify cilnidipine and valsartan concentrations in rat plasma [23-33]. Six healthy rats (200-400 g) were used for conducting in vivo studies. After an initial period of acclimatization for 1 week to laboratory conditions, the rats were randomly selected and administered the dose. In this study, a single dose was designed as, one-way cross over study with a washout period of 14days. The protocol followed in experimental was under Animal Ethical Guidelines (reg. No.-1153/PO/Re/S/08/CPCSEA) for investigations in laboratory animals and approved by the Animal Ethics Committee. Animals have fasted for $2 \mathrm{~h}$ after dose administration. A synthetic mixture of CLD $(1 \mathrm{mg} / \mathrm{kg})$ and VAL $(1 \mathrm{mg} / \mathrm{kg})$ dose was administered orally. A total of 13 blood collection time points including the pre-dose sample $(0,0.5,1,2,3,4,5,6,7,8,10,12$, and 24 h). Vacutainers containing $K_{2}$ EDTA as an anticoagulant was used for collecting blood samples separately. The obtained plasma sample was stored until analysis. The sample was separated from plasma by using a cooling centrifuge at 4000-7500 rpm for CLD and VAL. After analysis, the pharmacokinetic parameters were computed using Kinetica software version 5.0.

\section{In vivo data analysis}

To determine the various pharmacokinetic parameters, the plasma concentration of cilnidipine and valsartan at different time intervals was subjected to quantitative analysis shown in Fig. 3. Pharmacokinetic parameters like maximum plasma concentration $\left(C_{\max }\right)$, time to reach maximum concentration $\left(T_{\max }\right)$, and area under the plasma concentration-time curve $\left(\mathrm{AUC}_{0 \rightarrow \infty}\right)$ was calculated using the Kinetica software version 5.0 [22].

\section{Comparative study of the developed method}

The developed method compared with the previously reported method by Lee et al., [7] the $C_{\max }$ observed by the previous method were $8.3 \pm 4.5$ and $4612.6 \pm 2302.4$

Table 7 Comparative study of pharmacokinetic parameters

\begin{tabular}{llll}
\hline Parameters & \multicolumn{2}{l}{ Developed pharmacokinetic method } & \multicolumn{2}{l}{ Previous pharmacokinetic method [7] } & CLD \\
\cline { 2 - 3 } & CLD & VAL & $8.3 \pm 4.5$ \\
\hline$C_{\max }(\mathrm{ng} / \mathrm{mL})$ & $338 \pm 13.85$ & $1282.21 \pm 39.23$ & 2.5 \\
$T_{\max }(\mathrm{h})$ & $3.0 \pm 0.81$ & $4.0 \pm 0.89$ & $3612.6 \pm 2302.4$ \\
$\mathrm{AUC}_{\text {last }}(\mathrm{ng} \mathrm{h} / \mathrm{mL})$ & $1069.04 \pm 36.93$ & $5132.8 \pm 76.76$ & 4 \\
$\mathrm{AUC}_{0-\infty}(\mathrm{ng} \mathrm{h/mL})$ & $1117.84 \pm 54.90$ & $5584.89 \pm 125.7$ & $43.1 \pm 22.5$ \\
\hline
\end{tabular}


$\mathrm{ng} / \mathrm{mL}, T_{\max }$ were found to be 2.5 and $4 \mathrm{~h}, \mathrm{AUC}_{\text {last }}$ were reported as $38.7 \pm 19.7$ and $25,864.5 \pm 12,611 \mathrm{ng} / \mathrm{mL}$, and $\mathrm{AUC}_{\infty}$ were reported as $43.1 \pm 22.5$ and $27,498.1 \pm$ $13,676 \mathrm{ng} \times \mathrm{h} / \mathrm{mL}$ for CLD and VAL, respectively [7].

In the developed method, $C_{\max }$ were found to be 338 \pm 13.85 and $1282.21 \pm 39.23 \mathrm{ng} / \mathrm{mL}, T_{\max }$ were found to be $3.0 \pm 0.81$ and $4.0 \pm 0.89 \mathrm{~h}, \mathrm{AUC}_{\text {last }}$ were $1069.04 \pm$ 36.93 and $5132.8 \pm 76.76 \mathrm{ng} \times \mathrm{h} / \mathrm{mL}$, and $\mathrm{AUC}_{\infty}$ were $1117.84 \pm 54.90$ and $5584.89 \pm 125.7 \mathrm{ng} \times \mathrm{h} / \mathrm{mL}$ for CLD and VAL, respectively. The result is shown in Table 7.

\section{Conclusion}

A simple, accurate, precise, and rapid UV-liquid chromatographic method for simultaneous estimation of cilnidipine and valsartan in rat plasma is validated as per the USFDA guidelines. The method is found to be suitable for the study of pharmacokinetic application in rats. The cost-effectiveness, simplicity of the assay, and usage of liquid-liquid extraction make it an attractive procedure in high-throughput bioanalysis of cilnidipine and valsartan. From the results of all the validation parameters, we can conclude that the developed method can be useful routinely for bioavailability and bioequivalence studies and therapeutic drug monitoring with the desired precision and accuracy.

\section{Abbreviations}

RP-HPLC: Reversed-phase high-performance liquid chromatography; ODS: Octa-decyl silane; v/v: Volume by volume; $C_{\text {max }}$ : Concentration maxima; $T_{\text {max: }}$ Therapeutic maxima; CLD: Cilnidipine; VAL: Valsartan; CV: Coefficient of variance; LOD: Limit of detection; LOQ: Limit of quantitation; DAD: Diode array detector

\section{Acknowledgements}

The authors gratefully acknowledge Amrutvahini College of Pharmacy, Sangamner (Maharashtra, India), for providing necessary facilities for carrying out this study and are also grateful to all the staff and friends for their help and support.

\section{Authors' contributions}

RNK was design and optimized method. The manuscript was drafted by RNK. The method was performed and validated by SSY. AGM have contributing in grammatically molding and writing of manuscript and gives their scientific suggestion. All authors have read and approved the manuscript.

\section{Funding}

There is no funding source for this project.

\section{Availability of data and materials}

All data and materials are available upon request.

\section{Ethics approval and consent to participate}

Not applicable

\section{Consent for publication}

Not applicable

\section{Competing interests}

The authors declare that they have no competing interests.

\section{Author details}

'Department of Pharmaceutical Chemistry, Amrutvahini College of Pharmacy, Affiliated Savitribai Phule Pune University, Sangamner, Maharashtra 422608, India. ${ }^{2}$ Department of Quality Assurance Techniques, Amrutvahini College of Pharmacy, Affiliated Savitribai Phule Pune University, Sangamner, Maharashtra, India.

Received: 19 August 2020 Accepted: 3 December 2020

Published online: 07 January 2021

\section{References}

1. Chandra SK, Ramesh G (2013) The fourth-generation calcium channel blocker cilnidipine. Ind. Heart J 65:691-695. https://doi.org/10.1016/j.ihj. 2013.11.001

2. Yoshimoto R, Dohmoto H, Yamala K, Goto A (1991) Prolonged inhibition of vascular contraction and calcium influx by the novel 1, 4 dihydropyridine calcium antagonist cilnidipine (FRC-8653). Japan J Pharmacol 156:225-229

3. Neil O (2006) The Merck index an encyclopedia of chemical and biological, vol 48, 14th edn. Merck \& Co. Inc, p 379

4. Nadeem S, Asif H, Lakshita C, Shamsher A, Moloy M, Parminder SB (2011) Pharmacological and pharmaceutical profile of valsartan: a review. J Appl Pharm Sci 01(04):12-19

5. Goodman and Gilman's (2001) The pharmacology basis of therapeutics. Medical publishing Division, New York, pp 249-260

6. Shinji T, Denan J, Shizuka A, Kazumi N, Mizuo M (2013) Powerful vascular protection by combining cilnidipine with valsartan in stroke-prone, spontaneously hypertensive rats. Hypert Rese 36:342-348

7. Jieon L, Howard L, Kyungho J, Kyoung SL, Dongseong S, Kyung S-Y (2014) Evaluation of the pharmacokinetic and pharmacodynamic drug interactions between cilnidipine and valsartan, in healthy volunteers. Drug Design Devel Ther 8:1781-1788

8. Heon WL, Ji-Hyung S, Hyun-Su L, Seo-Young J, Young-WC, Kyung-Tae L (2008) Development of a liquid chromatography/negative-ion electrospray tandem mass spectrometry assay for the determination of cilnidipine in human plasma and its application to a bioequivalence study. J Chromatogr B 862:246-251

9. Xianhua Z, Suodi Z, Rongsheng Z, Jin O, Li X, Willy RG (2007) Determination of cilnidipine, a new calcium antagonist, in human plasma using highperformance liquid chromatography with tandem mass spectrometric. Anal Chim Acta 600:142-146

10. Alagar R, Ashwini David B, Rao KN, Selva K (2015) A new analytical method development and validation for the estimation of olmesartan medoxomil and cilnidipine in its pharmaceutical dosage form by UPLC as per ICH guidelines D2. Asian J Rese Bio Pharm Sci 3(2):78-86

11. Amit SM, Manjusha ND, Sanjay DS (2014) Development and validation of an analytical method for simultaneous estimation of cilnidipine and olmesartan medoxomil in bulk and tablet dosage form by RP-HPLC. Int J Pharm Pharm Sci 7(6):508-511

12. Krishnaiah CH, Reddy RA, Ramesh K, Mukkanti K (2015) Stability-indicating UPLC method for determination of valsartan and their degradation products in active pharmaceutical ingredient and pharmaceutical dosage forms. J Pharm Biomed Anal 53:483-489

13. Jirí V (2015) A new, rapid, stability-indicating UPLC method for separation and determination of impurities in amlodipine besylate, valsartan, and hydrochlorothiazide in their combined tablet dosage form. J Pharm Biomed Anal 109:36-44

14. Vishal G, Rajeshwari R, Ranjeet P, Dash MN (2013) Simultaneous quantification of aliskiren, valsartan and sitagliptin by LC with fluorescence detection: evidence of pharmacokinetic interaction in rats. Chromatographia 76(9-10):515-521

15. Rasha A, Shaalan TS, Belal FA, El Y, Sohila M (2013) Validated stabilityindicating HPLC-DAD method of analysis for the antihypertensive triple mixture of amlodipine besylate, valsartan and hydrochlorothiazide in their tablets. Arab J Chem 10(1):S1381-S1394

16. Hiten JS, Naresh B, Kataria GS, Chagan NP (2009) Simultaneous LC-MS-MS analysis of valsartan and hydrochlorothiazide in human plasma. Chromatographia 69(9-10):1055-1060

17. Nozomu K, Hiroto K (2007) Development and validation of a method for the quantitative determination of valsartan in human plasma by liquid chromatography-tandem mass spectrometry. J Pharm Biomed Anal 43: 1769-1774 
18. Senthamil SP, Veeran GK, Mandal U, Sam-Solomon WD, Pal TK (2007) Simultaneous determination of fixed-dose combination of nebivolol and valsartan in human plasma by liquid chromatographic-tandem mass spectrometry and its application to a pharmacokinetic study. J Chromatogr B 858(1-2):143-150

19. Shankar GG, Pragney D, Madhusudana K, Ramakrishna S (2014) Simultaneous determination of amlodipine, valsartan, and hydrochlorothiazide by LC-ESI-MS/MS and its application to pharmacokinetics in rats. J of Pharm Ana 6(4):399-406

20. del RB M (2009) Determination of losartan, Telmisartan, and valsartan by direct injection of human urine into a column-switching liquid chromatographic system with fluorescence detection. J Pharm Biomed Anal 50:194-199

21. U. S .Department of Health and Human Services (2013) Food and Drug Administration: guidance for industry, bioanalytical method validation, September

22. Eboka MB, Sabi M, Janvier EA, Run Z, Li Q, Li D (2016) Simultaneous determination of a fixed-dose combination of lercanidipine and valsartan in human plasma by LC-MS-MS: application to a pharmacokinetic study. J Chromatogr Sci 54(9):1553-1559

23. Aruna G, Bharathi K, Prasad K (2017) Development and validation of bioanalytical HPLC method for simultaneous estimation of clinidipine and nebivolol in human plasma. Int J Pharm Pharm Sci 9(10):253-259

24. Mir-Ali F, Parisa K, Azar P (2016) Simultaneous determination of atorvastatin and valsartan in human plasma by solid- based disperser liquid-liquid microextraction followed by high-performance liquid chromatographydiode array detection. J Chromatogr B 1017:62-69

25. Jiezhao Z, Meilling C, Li Y, Yu F, Xiaohui C, Hui ZXM (2017) Simultaneous determination of metolazone and valsartan in plasma by on-line SPEcoupled with liquid chromatography/tandem mass spectrometry. Eur J of Mass Spect 23(5):305-312

26. Jaldeepsinh VR, Maheshwari DG (2015) Development and validation of second order derivative spectrophotometric method for simultaneous estimation of cilnidipine and valsartan in synthetic mixture. Ame J of Pharm Tech Res 2(5):313-323

27. Bhole RP, Pawara VC, Chitlange SS (2015) Development and validation of HPLC method for simultaneous estimation of cilnidipine and valsartan in bulk and tablet dosage form. Res \& Re J of Pharm Sci 6(2):28-36

28. Pooja JP, Ankit BC, Vijay PJ, Ruchi PS (2017) Stability indicating RP-HPLC method development and validation for estimation of cilnidipine and valsartan. World J Pharm Pharm Sci 5(5):1231-1245

29. Bhoomi DA, Aniket B, Chaudhary PJ, Parmar VN (2016) Development and validation of reverse-phase high-performance liquid chromatography method for simultaneous estimation of nebivolol $\mathrm{HCl}$ and clinidipine in combined tablet dosage form. Pharm \& Biom Eva 3(2):208-214

30. Pavan KV, Lokeswara G, Haribaskar V, Gobinath M (2015) Development and validation of RP-HPLC method for simultaneous estimation of metoprolol succinate and cilnidipine in combined tablet dosage form. Int J Pharm 5(4): 1196-1202

31. Priyanka RP, Nilam P, Samir KS (2015) Analytical method development and validation for simultaneous estimation of nebivolol hydrochloride and cilnidipine in the combined dosage form. J Chem Pharm Res 7(9):951-960

32. Ritesh PB, Vinayak CP, Sohan SC, Sager BW (2015) Development and validation of HPLC method for simultaneous estimation of cilnidipine and valsartan in bulk and tablet dosage form. Int J of Pharm Chem Ana 2(1): 102-107

33. Sunitha N, Subhash CM, Sai SJ, Venu A, Narasimha BV, Appa B (2015) Method development and validation of RP-HPLC method for the simultaneous estimation of olmesartan and cilnidipine in bulk and formulations. Int J of Pharm Res \& Allied Sci 4(3):127-135

\section{Publisher's Note}

Springer Nature remains neutral with regard to jurisdictional claims in published maps and institutional affiliations.

\section{Submit your manuscript to a SpringerOpen ${ }^{\odot}$ journal and benefit from:}

- Convenient online submission

- Rigorous peer review

- Open access: articles freely available online

High visibility within the field

- Retaining the copyright to your article

Submit your next manuscript at $\boldsymbol{\nabla}$ springeropen.com 